\title{
The Interplay of the Desired and Undesired Selves in Everyday Consumption
}

*Chihling Liu, Assistant Professor of Consumer Behavior and Marketing ${ }^{1}$

Margaret K. Hogg, Professor of Consumer Behavior and Marketing ${ }^{2}$

*Corresponding author

${ }^{1}$ Lancaster University Management School,

Charles Carter Building, Lancaster, Room: D36, LA1 4YX, UK

Tel: +44 (0) 1524 510197, Fax: +44 (0) 1524510935

Email: Chihling.Liu@lancaster.ac.uk

${ }^{2}$ Lancaster University Management School

Charles Carter Building, Lancaster, Room: D42, LA1 4YX, UK

Tel: +44 (0) 1524 510767, Fax: + 44 (0) 1524510935

Email: m.hogg@lancaster.ac.uk 


\section{Introduction}

In contemporary society, the endeavor to create or sustain the self is often closely intertwined with consumption (Arnould \& Thompson, 2005; Belk, 1988; Firat \& Venkatesh, 1995; Kleine, Kleine, \& Kernan, 1993; Wattanasuwan, 2005). Consumption can function as a mechanism generating meanings that we desire for self-creation. Individuals use the symbolic meanings embedded in their consumption choices to relate to the outside culturally constituted world, and to reflect their desired/accepted or undesired/rejected self (Belk, 1988; Berger \& Heath, 2007; Solomon, 1983). This means that while we can accept symbolic meanings with positive connotations, we can also reject symbolic meanings that we find undesirable (Hogg, Banister, \& Stephenson, 2009; Levy, 1959; Thompson \& Haytko, 1997). Consumption objects can be used not only for impression management, but also to serve as stimuli in guiding an individual's behavior in different social contexts (Solomon, 1983; Wright, Claiborne, \& Sirgy, 1992). As consumers, we avail ourselves of consumption choices to help us through life transitions, manage social relationships, and facilitate a sense of wellbeing across social contexts (e.g., Elliott \& Wattanasuwan, 1998b; Liu, Keeling, \& Hogg, 2016; Schouten, 1991; Thompson \& Hirschman, 1995). Past consumer research has often focused on understanding consumption choices from the perspective of the desired self (e.g., who I want to be). In this chapter, we seek to also draw attention to a growing research agenda that seeks to better understand the role of the undesired self (e.g., who I do not want to be) in driving consumers' (anti-)consumption choices.

This chapter begins with an overview of the desired and the undesired self in consumer research, illustrating how individuals use their (anti-)consumption choices to approach their desired selves and avoid their undesired selves. Following this overview, we 
discuss the roles of possible, situational and relational selves in regulating our (anti)consumption activities and that enable the selves to be approached or avoided. Building on this discussion, we illuminate how individuals' need to belong influences their decisions in terms of which selves to approach or avoid in specific social contexts. We close this chapter by presenting a more complex picture of the intricate interplay between individuals' desired and undesired selves and the implications for future studies on the links between self, gender and consumption today.

\section{Overview of the desired and the undesired self in consumer research}

Levy's (1959) work on 'Symbols for sale' paved the way for a series of consumer studies that focused on the intimate inter-relationships between self, identity and consumption. Since then, studies of symbolic consumption have flourished. Many of these studies embrace the symbolic self-completion thesis (Wicklund \& Gollwitzer, 1982) and examine how consumers achieve their desired self by buying and accumulating the ideal characteristics associated with a product or service. These studies show how consumers engage in consumption activities to claim and extend their self-definitions (Belk, 1988; Muniz Jr \& O'Guinn, 2001), fulfil life's fantasies (Belk \& Costa, 1998; Holbrook \& Hirschman, 1982), achieve their ideal self-presentations (Askegaard, Gertsen, \& Langer, 2002) and obtain social approval for their desired self (Schau \& Gilly, 2003). Failing to acquire the ideal characteristics for endorsing the desired self often leads to a sense of "shattered self" (see Üstüner \& Holt, $2007^{3}$ ). Similarly, supporters of "liberatory postmodernism" (Firat \& Venkatesh, 1995) have

\footnotetext{
${ }^{3}$ Ustuner and Holt (2007, p.52) used "shattered identities" to capture the sense of lost dreams experienced by young Turkish urban migrant women who aspired to emancipation as represented by city women's lives, but whose own experiences of social, cultural and economic barriers meant they found it very difficult, if not impossible, to achieve their dreams.
} 
emphasized the centrality of human agency in managing and carving out a meaningful existence through consumption. "Liberatory postmodernism" focuses on the ways in which consumers engage in consumption activities as a way of producing multiple desired identities and constructing (hyper)realities at will. Hyperreality refers to the current condition of postmodernity where "simulation is substituted for genuine experience, and perhaps even preferred" (Rose \& Wood, 2005, p.286). While these desired identities/(hyper)realities often conflict (e.g., Ahuvia, 2005; Tian \& Belk, 2005), Firat and Venkatesh (1995) would argue that these conflicts are unproblematic for consumers' identity work and their sense of wellbeing because the authors' idea of the subject is decentered and fragmented. In sum, although not all consumer researchers agree that consumers experience little or no anxiety/uncertainty over identity conflicts (e.g., Thompson \& Haytko, 1997), researchers are in general agreement that consumers consume to enhance or reflect their desired self.

This focus on examining the desired self has led consumer researchers to concentrate predominantly on the positive drivers within the nexus of identity, self and consumption. However, in social psychology literature, there is evidence that suggests the undesired self may play at least as central a role in our everyday social conduct and experiences of the self (Carver, Lawrence, \& Scheier, 1999; Heppen \& Ogilvie, 2003; Ogilvie, 1987). Markus and Nurius (1986), for example, note the significance of negative possible selves in stifling individuals' attempts to change or develop. This is because when a negative possible self is activated, its associated negative affect works to undermines individuals' sense of self. In addition, Ogilvie's (1987) empirical study comparing the undesired self with the ideal self (who I would like to be) showed that the implicit reference standard that individuals employ, in order to evaluate their present-day life satisfaction, is based more upon how close to or distant they are from their most negative self-concepts than their ideal ones. This finding is significant because firstly, it contradicts a widely supported theoretical view that life 
satisfaction is achieved only when certain ideal goals are met. Secondly, this finding suggests that the underlying mechanism that is more powerful in driving satisfaction is not the concept of the ideal self or the ought self (who I should be), but rather the concept of the undesired self. Complementing Ogilvie's (1987) study, Carver et al.'s (1999) work shows that the discrepancy between the actual self (who I see myself as) and the feared self (who I am afraid of becoming) was the strongest predictor for dejection-related emotions such as depression and its conceptual opposite, happiness. These authors also found that this feared discrepancy was a more powerful indicator for agitation-related emotions such as anxiety, guilt, and their conceptual opposite, contentment, than the ought discrepancy. Taken together, Carver et al.'s (1999) findings point to the influential role the undesired self plays in generating a range of affective outcomes, which in turn could have a profound impact on people's psychological functioning and their ensuing coping behavior.

In line with this stream of psychology literature, consumer research interests in the undesired self in motivating consumers' (anti-)consumption choices have grown in the last 10-15 years ( Hogg \& Banister, 2001; Hogg et al., 2009; Lee, Motion, \& Conroy, 2009; Sivanathan \& Pettit, 2010). In contrast to positive consumption choices as typically investigated (Solomon, 1988), for example, Hogg (1998) drew on Solomon's research to propose the concept of "consumption anti-constellations" that focus on consumers' creation of meaning via negative, rejected choices. According to Hogg (1998), there are two types of negative choices in regards to consumption anti-constellations: (1) "non-choice", and (2) "anti-choice". "Non-choice" refers to the products and services that are simply not purchased as a result of inadequate income and resources (e.g. affordability, availability, and accessibility). This perspective has often been investigated in the context of vulnerable consumers. For instance, Hill's (1991) work found that contrary to the prevalent beliefs that homeless women do not appreciate the things they are given because they are 'lazy' (e.g., 
avoid cleaning their own living spaces, discard clothing rather than wash it etc.), these women are doing so in order to avoid forming attachments to the things that can be easily taken away (e.g., homeless shelters regularly have rules that limit the length of stay to no more than three weeks). Here it is the undesired self (e.g., the fear of becoming attached to things that will be eventually taken away) that drives these women's detachment from the things they have been given in the shelter. Furthermore, Adkins and Ozanne (2005) show how the undesired self (low literacy in this case) could have a negative impact on consumers' everyday social interactions and greatly shape and limit their consumption activities. For example, one informant in their study followed a rigid routine food-shopping list (e.g., peanut butter, jelly, sandwich meat) for 30 years (albeit, he was tired [sic] of this routine) due to his fear of exposing his low literacy skills. Üstüner and Holt's paper (2007) further demonstrates how the inability to acquire the goods associated with the desired lifestyle (e.g., mobilize to a higher social status) could leave one feeling immobilized, depressed and trapped in an undesired self. This stream of research has thus tried to establish the potential impact of nonchoice in perpetuating an individual's undesired self and his/her consumption activities. We acknowledge the importance of non-choice in shaping consumers' decision-making (e.g., transformative consumer research and its focus on vulnerable consumers) (see Mick, 2006). However due to the limited space, the focus of the rest of this chapter will be on providing a more in-depth understanding of consumers' (anti-)choices and the role of the desired/undesired self in regulating individuals' everyday consumption activities.

In contrast to non-choice, "anti-choice" refers to products and services that consumers deliberately do not choose because they are considered to be incompatible with their values, lifestyles, self-images and preferences (Hogg, 1998). The incompatibility often leads to consumption abandonment, avoidance and aversion. Whereas aversion is defined as the negative affect of attitudes, including dislike, disgust and revulsion, avoidance (the 
deliberate rejection of a certain product or service) and abandonment (discarding something previously possessed) are more likely to flow from the behavioral consequences of such attitudes (Hogg, 1998; Hogg et al., 2009). Building on Bourdieu (1984), for instance, Hogg and Banister (2001) argue that in order to fully capture the formation of consumption tastes, we need to recognise and understand the meanings attached to distastes. In other words, without a more complete understanding of the negative self in anti-consumption, we cannot fully appreciate the concept of the positive self in symbolic consumption. Supporting this, Banister and Hogg's (2004) paper on negative symbolic consumption showed that the majority of their informants' consumption choices seemed to have been predominantly driven by the intention to avoid, distinguish or distance themselves from the user images that they perceived to be undesirable. These user images are treated as negative stereotypes that one strives to avoid in order to maintain one's sense of self (Hogg et al., 2009; Lee et al., 2009). Sivanathan and Pettit's experimental study (2010) found that consumers protect the self through status consumption because "the experience of owning status goods provides important psychological armor to protect the self against the arrows of negativity (e.g., the implications of not owning these goods)". That is, (anti-)consumption activities here are powerfully driven by the motivation to protect self-integrity/self-esteem (Hogg et al., 2009; Sivanathan \& Pettit, 2010) from the underlying negativities in the self (e.g., who I am not), particularly the highly cathected self-identity (Wicklund \& Gollwitzer, 1981). These earlier findings were reinforced by the results from Bahl and Milne's (2010) qualitative study that also established the presence of undesired selves in influencing all the self-regulation processes behind their informants' consumption decision-making.

\section{Self-regulation through consumption}


We regulate ourselves (whether it be our desired or undesired selves) by envisaging our possible selves (Markus \& Nurius, 1986), locating our situational selves (Belk, 1975), and managing our relational selves (Andersen \& Chen, 2002). In the following sections, we begin by first introducing the key parts of each of these theoretical concepts (possible, situational and relational selves) in terms of their respective role(s) in influencing individual's ongoing self-regulatory behavior and specifically in the (anti-)consumption context. Secondly, we then summarize how these concepts potentially come together in regulating consumers' (anti)consumption activities that enable the different selves to be approached or avoided (Edson Escalas \& Bettman, 2005; Reed, 2004; Schouten, 1991).

The possible selves. The notion of possible selves indicates individuals' selfknowledge of what they might become, what they would like to become, and what they are afraid of becoming (Markus \& Nurius, 1986). Self-knowledge here refers to one's perceptions of future selves, including hopes, fears and fantasies, which may not have been validated or confirmed by social experiences. Possible selves are characterized as the "cognitive manifestations of enduring goals, aspirations, motives, fears and threats" (Markus \& Nurius, 1986, p.954). That is, motivation is central to this concept of possible selves (Curry, Trew, Turner, \& Hunter, 1994), and serves to organize and fuel action and (consumption) behavior (Frazier, Hooker, Johnson, \& Kaus, 2000).

According to van Dellen and Hoyle (2008), there are two potential mechanisms by which possible selves may trigger regulatory behavior. First, possible selves may prioritize goal-congruent behavior because possible selves increase the desirability and accessibility of a particular aspect of the future self (Fishbach, Friedman, \& Kruglanski, 2003). Successful persuasion, then, prescribes specific self-regulatory strategies to adjust behavior without 
reference to the current self (e.g., who I perceive myself to be right now). Consumer research on the link between reference group(s) and brand usage has demonstrated how consumers could buy into certain brands because of the brands' associations with specific reference groups that symbolize aspects of an individual's desired future self (Elliott \& Wattanasuwan, 1998a; McCracken, 1989) or avoid these brands due to their undesired future self (Lee et al., 2009). In the context of social media, for instance, consumers are found to actively associate themselves with specific brands on their Facebook pages as subtle cues to represent their actual and/or ideal selves (although in reality, they may not be able to afford these brands) (Hollenbeck \& Kaikati, 2012). Secondly, possible selves may facilitate behavior that is to be approached or avoided through a process of comparing the current self with the possible self. Such intra-self-comparisons not only promote self-regulation but also good feelings (Oyserman, Bybee, Terry, \& Hart-Johnson, 2004). These intra-self-comparisons can induce positive beliefs or self-feelings so that the current self is not seen as an immutable attribute but rather one where change is possible (Markus \& Nurius, 1986). For example, much consumer research on self-presentation illustrates how consumers conduct selfadornment/care activities to transform their natural self in an attempt to facilitate desired changes in the current lifestyle (McAlexander \& Schouten, 1989) and/or avoid presenting perceived negative body images that may undermine their ability to gain social rewards and avoid social sanctions (Askegaard et al., 2002; Kinnunen, 2010; Thompson \& Hirschman, 1995).

Possible selves thus enable individuals to reflect upon and evaluate their current behaviors against what they envisage they would like to achieve in the future (vanDellen \& Hoyle, 2008). The emphasis on both motivation and self-evaluation underlines the powerful role of possible selves in one's ongoing self-regulatory behavior. However, as Schouten (1991, p.422) neatly put it, there are three ways in which consumers respond to their possible 
selves: "(1) with inaction, (2) with active rejection, or (3) with actualization and the incorporation of the possible self into a revised self-concept." Inaction occurs when consumers are in a state where uncertainties are great, thus leading to no attempts to change current consumption behaviors (e.g., when possible selves are not desirable enough to pursue or not undesirable enough to avoid; or when there are disagreements within the self about whether or not the possible self is desirable). Rejection occurs when a possible self is considered to be undesirable, not me or impossible to actualize. This often leads to the formation of another possible self and the associated (anti-)consumption activities. Finally, the more desirable and accessible a possible self seems to the consumer, the more s/he will be motivated to actualize it (e.g., via plastic surgery to transform the self and present a more desired, revised self). Conversely, the more undesirable a possible self seems, the more s/he will be motivated to avoid it (e.g., not to undertake plastic surgery to avoid becoming linked to what others might perceive to be 'superficiality'). Having discussed the possible self and the important role it plays in understanding consumer behavior, it is important to note that the contents of individuals' possible selves are often conditioned by the types of situations they encounter (e.g., whom I would like to be or not be when I am a student in a lecture theater room can be dramatically different from who I want to be as a visitor (or guest) when I am in Disneyland!). This then leads to our next discussion on the situational self.

The situational self. Consumers are likely to experience and subscribe to multiple self-images within their life span. The situational self-image, like the possible self, is influenced by the individual's goal pursuit behavior, but the emphasis here is placed more on its sensitivity to the situational context. Schenk and Holman (1980) define situational selfimage as the self-meanings, including attitudes, perceptions and feelings, that the individual wishes to communicate to others. The situational demands s/he perceives then influence and regulate his/her choice with regards to which self to express (e.g., the actual, ideal or ought 
self inter alia). Once the individual decides on which self-image to express in a specific situation, s/he then searches for ways of enacting this self-image (Sirgy, 1982). For example, the thesis of self-image/product-image congruity theory (Sirgy, 1985) argues that consumers use specific product characteristics (i.e., product symbolism) to enable self-expression (and thus avoid those images that might not represent who they are). In a situation where the individual wishes to depict a successful professional self-image, for instance, s/he may decide to wear a tailored suit that would be a cultural representation of such a professional image (at least in Western culture), not a tracksuit that is commonly linked to a more relaxed, chilledout home image. According to Solomon (1983), product symbolism also serves as a priori stimuli to behavior. That is, product symbolism facilitates not only self-expression/definition, but also related role performances (e.g., by wearing a suit in a professional situation, I will also feel and act more confidently and professionally; I avoid wearing a tracksuit in a professional context because it potentially risks making me look and feel less professional and less eager to 'get things done'). The more insecure we are in terms of performing a specific role, the more likely we are to turn to product symbolism in order to conceal and/or compensate for this insecurity. This argument is in line with the self-completion theory (Wicklund \& Gollwitzer, 1982) that we introduced earlier.

In effect, the self is malleable, multifaceted and encompasses a wide variety of selfconcepts, with different selves emerging on different occasions (Aaker, 1999; Markus \& Kunda, 1986; Turner, 1985). The malleability of the self implies that people will have fundamentally different values, preferences and dislikes, and make fundamentally different choices, based upon which self is more salient at the time (Markus \& Kunda, 1986). Preferences are not always fixed but constructed, influenced and altered by the elicitation context (LeBoeuf, Shafir, \& Bayuk, 2010; Payne, Bettman, \& Johnson, 1992). Such momentary/situational salient self-identification drives specific goal pursuits (Chartrand, 
Huber, Shiv, \& Tanner, 2008) and plays a key role in influencing individuals' (anti)consumption choices (Belk, 1975). Specifically, when the momentarily salient self-identity surfaces, consumers adopt consumption values and traits associated with that self in order to reinforce their momentary self-image and shape identity-congruent choices (Sirgy, 1982). Wakefield and Inman's (2003) experimental study, for example, suggests that consumers are generally less price sensitive when buying products and services that contain hedonic characteristics (e.g., purchasing ice cream - where the hedonic self tends to surface and become the desired self in this situation) than the products or services that have more functional characteristics (e.g., purchasing paper towels - where the functional self tends to surface). Such fluctuation in the situational self may then have a profound impact on consumers' post-purchase satisfaction, as LeBoeuf et al. (2010) found in their study where their participants experienced regret/less satisfaction when the salient self-identity during post-choice consumption conflicted with the self-identity that was salient during the consumption decision-making process. This finding points to the complex interplay amongst the distinct situational self-images, and between the desired and the undesired selves (and how they seek to approach or avoid specific consumption activities or experiences).

The possible self and the situational self together tell us (1) that depending on situational cues, one self-aspect and its associated possibilities (e.g., hopes, fears and fantasies) may become dominant in a given situation, but this self-aspect may not necessarily be dominant in another context, and (2) about the temporal nature of one's perceived desired and undesired selves. The relational self that we discuss next adds another layer of complexity to our extant understanding about the links between self and (anti-)consumption. This is because consumers' possible and situational selves are more often than not further conditioned by their (everyday) social relationships. 
The relational self. The basic notion that our cultural world - as well as the people we interact with - influence a sense of who we are has long been central to many disciplines (e.g. psychology, sociology). Such socio-cultural influences on the self often occur through the process of reflected appraisals (Rosenberg, 1979). That is, individuals' formation of selfconcepts is strongly influenced by their direct reflections on, for example, how others view them; and by how their self-view is weighted in relation to others' perceptions of themselves. This is especially the case when the others are considered to be the significant others whose views are particularly important and appreciated (Andersen \& Thorpe, 2009; Chen, Boucher, \& Tapias, 2006). A significant other in this case refers to "any individual who is or has been deeply influential in one's life and in whom one is or once was emotionally invested" (e.g., family members, close friends) (Andersen \& Chen, 2002, p.619). The relational self thesis thus focuses on how an individual's sense of self, including thoughts, feelings, beliefs and self-regulatory (consumption) strategies, is influenced by their relations with relevant significant others (Andersen \& Chen, 2002).

For example, under experimental conditions, those Catholic subjects who read a story describing a woman's sexual dream, followed by the exposure to a disapproving face of the Pope, experienced a lowered self-evaluation. However, those who were subsequently presented with a disapproving face of an unfamiliar other, showed no changes in their selfevaluation (Baldwin, Carrell, \& Lopez, 1990). The basic idea behind this experiment was that based on transference (i.e., past knowledge/experience learned from past relationships), individuals develop relational schemas that consist of interpersonal scripts. These scripts are concerned with the if-then dynamics that inform the individual of stereotypical relational patterns (e.g. if the Pope caught me reading inappropriate sexual materials, then he will not think I am a good person) (Baldwin, 1994). Individuals thus often conduct consumption activities based on the anticipated if-then dynamics in seeking to manage a social relationship 
(e.g., if I buy my girlfriend flowers, she will be happy and then I will be happy). However, such if-then dynamics become increasingly complex when there are multiple social relationships involved, including the relationship to our own selves.

Consumption activities are thus often aimed at juggling multiple relationship demands (Ahuvia, 2005; Thompson, 1996; Tian \& Belk, 2005). Thompson's (1996) work shows how working mothers' (anti-)consumption activities are often motivated by protecting or enhancing their significant others (e.g., husband, children). Nevertheless, while the ability to take care of loved ones enables these women to feel fulfilled, it can also lead to a sense of exhaustion. In addition, Liu, Keeling and Hogg (2012) found their informants to vary their self-adornment efforts as a way to achieve desired relationship outcomes, and to avoid a sense of negative self in relation to their significant others. In their study (Liu et al., 2012), Martha described how she used to wear layers of makeup in order to empower herself in social relationships, and to help her cope with memories of the interpersonal difficulties that she had faced during her turbulent teenage years. However, she also described how she distanced herself from layers of makeup in situations where she sought to build a more genuine relationship. Overall, the relational self drives individuals to maintain the (perceived) wellbeing of the relationship itself (Sedikides \& Brewer, 2001). This is because positive selfconcepts are often dependent upon (1) perceptions of individuals' significant others and (2) the fulfillment of the need to belong (Baumeister \& Leary, 1995). This brings us to the role of (anti-)consumption in enabling social connections in the face of situations which potentially involve social exclusion.

\section{Self, consumption and the need to belong}


The need to belong is believed to be a pervasive human motivation because a lack of interpersonal attachments is linked to a range of negative effects on health, adjustments and self-esteem (Baumeister \& Leary, 1995; Maner, DeWall, Baumeister, \& Schaller, 2007). As a result, many people see their desired self as the one that is able to fulfill the need to belong and the undesired self as the one that fails to do so. It is for this reason, when individuals encounter a sense of or possibilities of social rejection (i.e., decreased feelings of belongingness), they often experience an increased need to rebuild and maintain at least adequate levels of belonging (see Leary, Tambor, Terdal, \& Downs, 1995).

Consumer researchers often examine the link between the self and the need to belong via the context of reference groups (i.e., those groups or group members that are influential for one's identity formation) (Argo, White, \& Dahl, 2006; Wan, Xu, \& Ding, 2014; White \& Dahl, 2007). There are three typical types of reference groups: membership reference groups (i.e., the ones I see as positive and I actually belong to; e.g., my family, gender group), aspirational reference groups (i.e., the ones that I see as positive and I aspire to belong to; e.g., celebrities I admire, a desired social group membership), and dissociative/negative reference groups (i.e., the ones that I do not see myself as belonging to and want to avoid being associated with) (White \& Dahl, 2006). White \& Dahl (2007) demonstrate that consumers' consumption choices are driven by a desire to approach positive reference groups and avoid dissociative/negative reference groups. They found that consumers form negative self-brand connections with dissociative brands, and evaluate their goods more negatively (therefore avoiding buying these brands). Being identified with a dissociative brand can perpetuate individual consumers' undesired selves because the identification threatens their self-values and attitudes and/or their sense of belonging to perceived positive reference groups. However, in situations where social connection threats are likely to occur, consumers are often found to consume strategically in the service of affiliation (even though this means they will have to 
conform to the dissociative/negative reference groups). To give an everyday example, say someone associates Abercrombie \& Fitch (A\&F) with sexual objectification that underlines his/her undesired self and thus they seek as far as possible to avoid making any A\&F purchase. Yet, despite the negative associations that s/he feels with $A \& F$, when s/he finds himself/herself in a group that all express a liking for A\&F's clothing line, s/he may end up also buying from A\&F in order to fit in. This is especially the case for high self-monitors (who tend to change their behavior and attitudes to gain situational social acceptance and achieve the desired self) and/or in public situations where the conformity will be seen (Mead, Baumeister, Stillman, Rawn, \& Vohs, 2011). Wan et al.'s (2014) more recent study sheds more light on the boundary condition of this urge to conform. Their study found that, whereas socially excluded individuals did try to fit in by conforming to the consumption norms of a dissociative reference group, this tended to happen only when their informants perceived a high degree of the chance of successful re-affiliation. When socially excluded individuals thought there was a low chance of successful re-affiliation, they were found to appreciate their unique self and sought to differentiate themselves more from the dissociative group through their subsequent (anti-)consumption choices. In effect, people's (anti-)consumption choices act as signals of identity and they use these signals to construct, express and enact their desired selves (and avoid their undesired selves) in response to perceived changes in both situational and social conditions (Escalas \& Bettman, 2003).

People's desired and undesired selves are however malleable and context dependent. A formerly desired self-association with a reference group could quickly turn into an undesired one if members of a negative reference group start to also adopt that association (e.g., the 'cool' element of going to a specific night club for a teenager may evaporate if grandparents also started going there). Under these circumstances, individuals often seek to transit to a new identity in order to maintain a sense of the desired, positive self (e.g., by 
finding alternative ways of associating the self with the 'cool' element) (Berger \& Heath, 2007). That said, such transitions might not always be easy. A recent study on the link between religion and consumer identity, for example, illustrates how individual consumers who rejected their former Mormon religious beliefs and associated consumption activities had to be very selective in terms of who they revealed the rejection to, in order to avoid being seen as an outcast from the community/family (McAlexander, Dufault, Martin, \& Schouten, 2014). When their sense of belonging was in question, as the result of the rejection, many former Mormon followers sought to find an alternative source of social support in groups run by those who had also left the church (McAlexander et al., 2014). These groups helped these former Mormon followers to reestablish a sense of belonging and come to terms with their post-Mormon identity construction, and the lost social connections that had originally been enabled through association with the Mormon church.

\section{Implications for future gender research}

Consumer culture theory research points to the concept of conflicted selves in influencing individuals' identity projects and associated (anti-)consumption activities (Ahuvia, 2005; Arnould \& Thompson, 2005). Drawing on the dialogical self theory, for example, Bahl and Milne (2010) showed how consumption meanings varied across multiple selves and that a consumption choice could symbolize both the desired and the undesired self. For instance, Brad's account in their study showed that while Brad's critical self viewed eating donuts as constructing his undesired self (e.g., "Donuts, what a waste! You're fat. Like you know no girl will ever like you"), his open self saw donuts as a nice treat that is desirable for his sense of self (e.g., "Donuts are fun...Enjoy it for a second and get back to what you're doing") 
(Bahl \& Milne, 2010, p.183). Liu et al.'s (2016) work on everyday self-presentation provides another example of the potential conflicts between consumers' desired and undesired selves, and between their personal and relationship wellbeing. Employing women's makeup use as their empirical context, Liu et al. (2016) identified specific situations where their women informants tended to use makeup for the purpose of concealing their undesired selves. While their informants clearly gained a sense of personal and relationship wellbeing through selfconcealment, these women simultaneously experienced profound anxieties about the consequences of failing to conceal the self as well as a sense of despair and helplessness about the natural, unadorned self. Consequently, the unadorned self becomes something they tended to avoid or hate, undermining their overall sense of wellbeing.

The shared meanings (e.g., product symbolism) deeply ingrained in a given consumer culture enables individual consumers to undertake reflected appraisals (Rosenberg, 1979). Such consumer culture is learned through consumer socialization that plays an influential role in the formation of individuals' desired and undesired selves, leading to the acceptance or rejection of certain products, brands or services (i.e., symbolic pro- or anti-consumption activities) (Hogg et al., 2009; Solomon, 1988; Ward, 1974). What is desired versus what is not desired, however, are often fundamentally gendered (Bristor \& Fischer, 1993; Greendorfer \& Ewing, 1981; Otnes \& Zayer, 2012; West \& Zimmerman, 1987). Women, for instance, when compared to men, are more often socialized into the role of a caregiver, and pride themselves on their ability to maintain and foster close affiliations and relationships rather than on achieving a sense of autonomy (even though this may mean they need to sacrifice their personal wellbeing for relationship wellbeing) (Jack, 1991; Kaplan, 1986; Surrey, 1991). As a result, women's (anti-)consumption activities are often organized around and cultivated in the context of significant (family) relationships, reflecting a caring orientation (Thompson, 1996). This is in contrast to men whose everyday consumption 
experiences are often marked as a pursuit of masculinity (albeit self-defined) that values autonomous rebellions and personal achievements (Holt \& Thompson, 2004). Such pursuits (which potentially prevent men from engaging in activities that are deemed feminine), however, while enabling men to achieve their desired self, can also threaten their sense of wellbeing when they take extreme measures to demonstrate and achieve manhood (e.g., risky consumption) (Courtenay, 2000).

The traditional gendered definition of the desired and undesired selves, however, has been increasingly challenged in our society (at least in the Western context). This is because of the increasing gender equality (albeit challenges remain; e.g., feminism's fourth wave) (see Maclaran, 2015 for an overview), the increasing evidence of gender transgression acts (e.g., David Bowie) and growing acceptance/awareness of other gender categories (e.g., homosexuality, bisexuality, transgender etc.). Gender is now a complex socio-cultural field that no longer adheres to a set of rigid traditional beliefs that dictate how a man or woman should look and feel. An increasing number of people today refuse to be defined as male or female (BBC, 2016). Previous research has indicated that individuals' gendered identities and experiences influence who they see themselves as (not) becoming (e.g., the possible self) (Lips, 2004; Thompson, 1975); which self they do (or do not) present on what social occasions (e.g., the situational self) (Chusmir \& Parker, 1991); the centrality of relationships to their sense of self (e.g., the relational self) (Cross \& Madson, 1997); and who they do (or do not) identify themselves with (e.g., reference groups; the need to belong) (Gabriel \& Gardner, 1999). With the increasing problematization of the essentialist definition of gender and how gender is performed (Butler, 2004; West \& Zimmerman, 1987), there is much scope for future research to explore, examine and theorize (1) the marketization of gender fluidity, and (2) the role of gender fluidity in influencing (anti-)consumption norms and experiences, and the interplay of individual consumers' desired and undesired selves. Importantly, what do 
the blurring gender boundaries today mean for consumers' sense of wellbeing? Is it as "liberatory postmodernism" claims that consumers are able to enact different selves through consumption (thus, individuals can try on different gender identities, e.g., the phenomenon of 'the living dolls' where men transform themselves into dolls by squeezing into a second skin) without experiencing any internal conflicts and contradictions (Firat \& Venkatesh, 1995)? Or are there conflicts and contradictions still to be resolved during the consumption process of "gender switching" (e.g., cross-dressers who are different from transvestites, who are different again from transgenders (in addition, see for instance, Ekins and King 2006)? Can these conflicts be resolved through specific (anti-)consumption activities (cf., Ahuvia, 2005) or are there any trade-offs that need to be made? Answering these questions, we argue, is imperative for advancing conversations and thus for furthering our understanding of self, gender and consumption in contemporary societies in the globalized world.

\section{References}

Aaker, J. L. (1999). The malleable self: The role of self-expression in persuasion. Journal of Marketing Research, 36(1), 45-57.

Adkins, N. R., \& Ozanne, J. L. (2005). The low literate consumer. Journal of consumer research, 32(1), 93-105.

Ahuvia, A. C. (2005). Beyond the extended self: Loved objects and consumers' identity narratives. Journal of consumer research, 32(1), 171-184.

Andersen, S. M., \& Chen, S. (2002). The relational self: An interpersonal social-cognitive theory. Psychological review, 109(4), 619-645.

Andersen, S. M., \& Thorpe, J. S. (2009). An IF-THEN theory of personality: Significant others and the relational self. Journal of Research in Personality, 43(2), 163-170. 
Argo, J. J., White, K., \& Dahl, D. W. (2006). Social comparison theory and deception in the interpersonal exchange of consumption information. Journal of consumer research, 33(1), 99-108.

Arnould, E. J., \& Thompson, C. J. (2005). Consumer culture theory (CCT): Twenty years of research. Journal of consumer research, 31(4), 868-882.

Askegaard, S., Gertsen, M. C., \& Langer, R. (2002). The body consumed: Reflexivity and cosmetic surgery. Psychology \& Marketing, 19(10), 793-812.

Bahl, S., \& Milne, G. R. (2010). Talking to ourselves: A dialogical exploration of consumption experiences. Journal of consumer research, 37(1), 176-195.

Baldwin, M. W. (1994). Primed relational schemas as a source of self-evaluative reactions. Journal of Social and Clinical Psychology, 13(4), 380-403.

Baldwin, M. W., Carrell, S. E., \& Lopez, D. F. (1990). Priming relationship schemas: My advisor and the pope are watching me from the back of my mind. Journal of experimental social psychology, 26(5), 435-454.

Banister, E. N., \& Hogg, M. K. (2004). Negative symbolic consumption and consumers' drive for self-esteem: The case of the fashion industry. European Journal of Marketing, 38(7), 850-868.

Baumeister, R. F., \& Leary, M. R. (1995). The need to belong: desire for interpersonal attachments as a fundamental human motivation. Psychological Bulletin, 117(3), 497529.

Belk, R. W. (1975). Situational variables and consumer behavior. Journal of consumer research, 2(3), 157-164.

Belk, R. W. (1988). Possessions and the extended self. Journal of consumer research, 15(2), 139-168. 
Belk, R. W., \& Costa, J. A. (1998). The mountain man myth: A contemporary consuming fantasy. Journal of consumer research, 25(3), 218-240.

Berger, J., \& Heath, C. (2007). Where consumers diverge from others: Identity signaling and product domains. Journal of consumer research, 34(2), 121-134.

Bourdieu, P. (1984). Distinction: A social critique of the judgement of taste. Cambridge, MA: Harvard University Press.

Bristor, J. M., \& Fischer, E. (1993). Feminist thought: Implications for consumer research. Journal of consumer research, 19(4), 518-536.

Butler, J. (2004). Undoing gender. New York: Routledge.

Carver, C. S., Lawrence, J. W., \& Scheier, M. F. (1999). Self-discrepancies and affect: Incorporating the role of feared selves. Personality and Social Psychology Bulletin, 25(7), 783-792.

Chartrand, T. L., Huber, J., Shiv, B., \& Tanner, R. J. (2008). Nonconscious goals and consumer choice. Journal of consumer research, 35(2), 189-201.

Chen, S., Boucher, H. C., \& Tapias, M. P. (2006). The relational self revealed: Integrative conceptualization and implications for interpersonal life. Psychological Bulletin, 132(2), 151-179.

Chusmir, L. H., \& Parker, B. (1991). Gender and situational differences in managers' values: A look at work and home lives. Journal of Business Research, 23(4), 325-335.

Courtenay, W. H. (2000). Constructions of masculinity and their influence on men's wellbeing: a theory of gender and health. Social science \& medicine, 50(10), 1385-1401.

Cross, S. E., \& Madson, L. (1997). Models of the self: self-construals and gender. Psychological Bulletin, 122(1), 5-37.

Curry, C., Trew, K., Turner, I., \& Hunter, J. (1994). The effect of life domains on girls' possible selves. Adolescence, 29, 133-133. 
Ekins, R., \& King, D. (2006). The transgender phenomenon. London: Sage.

Elliott, R., \& Wattanasuwan, K. (1998a). Brands as symbolic resources for the construction of identity. International journal of Advertising, 17(2), 131-144.

Elliott, R., \& Wattanasuwan, K. (1998b). Consumption and the Symbolic Project of the Self. European Advances in Consumer Research, 3, 17-20.

Escalas, J. E., \& Bettman, J. R. (2003). You Are What They Eat: The Infulence of Reference Groups on Consumers' Connections to Brands. Journal of Consumer Psychology, 13(3), 339-348.

Escalas, J. E., \& Bettman, J. R. (2005). Self-construal, reference groups, and brand meaning. Journal of consumer research, 32(3), 378-389.

Firat, A. F., \& Venkatesh, A. (1995). Liberatory postmodernism and the reenchantment of consumption. Journal of consumer research, 22(3), 239-267.

Fishbach, A., Friedman, R. S., \& Kruglanski, A. W. (2003). Leading us not into temptation: Momentary allurements elicit overriding goal activation. Journal of Personality and Social Psychology, 84(2), 296.

Frazier, L. D., Hooker, K., Johnson, P. M., \& Kaus, C. R. (2000). Continuity and change in possible selves in later life: A 5-year longitudinal study. Basic and Applied Social Psychology, 22(3), 237-243.

Gabriel, S., \& Gardner, W. L. (1999). Are there" his" and" hers" types of interdependence? The implications of gender differences in collective versus relational interdependence for affect, behavior, and cognition. Journal of Personality and Social Psychology, $77(3), 642-655$.

Greendorfer, S. L., \& Ewing, M. E. (1981). Race and gender differences in children's socialization into sport. Research Quarterly for Exercise and Sport, 52(3), 301-310. 
Heppen, J. B., \& Ogilvie, D. M. (2003). Predicting affect from global self-discrepancies: The dual role of the undesired self. Journal of Social and Clinical Psychology, 22(4), 347368.

Hill, R. P. (1991). Homeless women, special possessions, and the meaning of" home": An ethnographic case study. Journal of consumer research, 18(3), 298-310.

Hogg, M. K. (1998). Anti-constellations: exploring the impact of negation on consumption. Journal of Marketing Management, 14(1-3), 133-158.

Hogg, M. K., \& Banister, E. N. (2001). Dislikes, distastes and the undesired self: conceptualising and exploring the role of the undesired end state in consumer experience. Journal of Marketing Management, 17(1-2), 73-104.

Hogg, M. K., Banister, E. N., \& Stephenson, C. A. (2009). Mapping symbolic (anti-) consumption. Journal of Business Research, 62(2), 148-159.

Holbrook, M. B., \& Hirschman, E. C. (1982). The experiential aspects of consumption: Consumer fantasies, feelings, and fun. Journal of consumer research, 9(2), 132-140.

Hollenbeck, C. R., \& Kaikati, A. M. (2012). Consumers' use of brands to reflect their actual and ideal selves on Facebook. International Journal of Research in Marketing, 29(4), $395-405$.

Holt, D. B., \& Thompson, C. J. (2004). Man-of-action heroes: The pursuit of heroic masculinity in everyday consumption. Journal of consumer research, 31(2), 425-440.

Inquiry, B. W. S. (2016). Do we need more than two genders? Retrieved from: http://www.bbc.co.uk/news/health-35242180

Jack, D. C. (1991). Silencing the self: Women and depression. Cambridge, MA: Harvard University Press.

Kaplan, A. (1986). The" self-in-relation": Implications for depression in women. Psychotherapy: Theory, Research, Practice, Training, 23(2), 234-242. 
Kinnunen, T. (2010). 'A second youth': pursuing happiness and respectability through cosmetic surgery in Finland. Sociology of Health \& Illness, 32(2), 258-271.

Kleine, R. E., Kleine, S. S., \& Kernan, J. B. (1993). Mundane consumption and the self: A social-identity perspective. Journal of Consumer Psychology, 2(3), 209-235.

Leary, M. R., Tambor, E. S., Terdal, S. K., \& Downs, D. L. (1995). Self-esteem as an interpersonal monitor: The sociometer hypothesis. Journal of Personality and Social Psychology, 68(3), 518-530.

LeBoeuf, R. A., Shafir, E., \& Bayuk, J. B. (2010). The conflicting choices of alternating selves. Organizational Behavior and Human Decision Processes, 111(1), 48-61.

Lee, M. S. W., Motion, J., \& Conroy, D. (2009). Anti-consumption and brand avoidance. Journal of Business Research, 62(2), 169-180.

Levy, S. (1959). Symbols for sale. Harvard Business Review, 37(4), 117-124.

Lips, H. M. (2004). The gender gap in possible selves: Divergence of academic self-views among high school and university students. Sex roles, 50(5-6), 357-371.

Liu, C., Keeling, D., \& Hogg, M. (2012). The Unspoken Truth: A Phenomenological Study of Changes in Women's Sense of Self and the Intimate Relationship with Cosmetics Consumption. Research in Consumer Behavior, 14, 89-107.

Liu, C., Keeling, D. I., \& Hogg, M. K. (2016). Strategy narratives and wellbeing challenges: the role of everyday self-presentation. Journal of Business Research, 69(1), 234-243.

Maclaran, P. (2015). Feminism's fourth wave: a research agenda for marketing and consumer research. Journal of Marketing Management, 31(15-16), 1732-1738.

Maner, J. K., DeWall, C. N., Baumeister, R. F., \& Schaller, M. (2007). Does social exclusion motivate interpersonal reconnection? Resolving the" porcupine problem.". Journal of Personality and Social Psychology, 92(1), 42-55. 
Markus, H., \& Kunda, Z. (1986). Stability and malleability of the self-concept. Journal of Personality and Social Psychology, 51(4), 858.

Markus, H., \& Nurius, P. (1986). Possible selves. American psychologist, 41(9), 954-969.

McAlexander, J. H., Dufault, B. L., Martin, D. M., \& Schouten, J. W. (2014). The Marketization of Religion: Field, Capital, and Consumer Identity. Journal of consumer research, 41(3), 858-875.

McAlexander, J. H., \& Schouten, J. W. (1989). Hairstyle changes as transition markers. Sociology and Social Research, 74(1), 58-62.

McCracken, G. (1989). Who is the celebrity endorser? Cultural foundations of the endorsement process. Journal of consumer research, 16(3), 310-321.

Mead, N. L., Baumeister, R. F., Stillman, T. F., Rawn, C. D., \& Vohs, K. D. (2011). Social exclusion causes people to spend and consume strategically in the service of affiliation. Journal of consumer research, 37(5), 902-919.

Mick, D. G. (2006). Meaning and mattering through transformative consumer research. Advances in consumer research, 33(1), 1-4.

Muniz Jr, A. M., \& O'Guinn, T. C. (2001). Brand community. Journal of consumer research, 27(4), 412-432.

Ogilvie, D. M. (1987). The undesired self: A neglected variable in personality research. Journal of Personality and Social Psychology, 52(2), 379-385.

Otnes, C. C., \& Zayer, L. T. (Eds.). (2012). Gender, culture, and consumer behavior. New York: Routledge, Taylor \& Francis.

Oyserman, D., Bybee, D., Terry, K., \& Hart-Johnson, T. (2004). Possible selves as roadmaps. Journal of Research in Personality, 38(2), 130-149.

Payne, J. W., Bettman, J. R., \& Johnson, E. J. (1992). Behavioral decision research: A constructive processing perspective. Annual review of psychology, 43(1), 87-131. 
Reed, A. (2004). Activating the self-importance of consumer selves: Exploring identity salience effects on judgments. Journal of consumer research, 31(2), 286-295.

Rose, R. L., \& Wood, S. L. (2005). Paradox and the consumption of authenticity through reality television. Journal of consumer research, 32(2), 284-296.

Rosenberg, M. (1979). Conceiving the self. New York: Basic Books.

Schau, H. J., \& Gilly, M. C. (2003). We are what we post? Self-presentation in personal web space. Journal of consumer research, 30(3), 385-404.

Schenk, C. T., \& Holman, R. H. (1980). A sociological approach to brand choice: The concept of situational self-image. Advances in consumer research, 7(1), 610-614.

Schouten, J. W. (1991). Selves in transition: Symbolic consumption in personal rites of passage and identity reconstruction. Journal of consumer research, 17(4), 412-425.

Sedikides, C., \& Brewer, M. B. (2001). Individual self, relational self, collective self: Psychology Press.

Sirgy, M. J. (1982). Self-concept in consumer behavior: A critical review. Journal of consumer research, 9(3), 287-300.

Sirgy, M. J. (1985). Using self-congruity and ideal congruity to predict purchase motivation. Journal of Business Research, 13(3), 195-206.

Sivanathan, N., \& Pettit, N. C. (2010). Protecting the self through consumption: Status goods as affirmational commodities. Journal of experimental social psychology, 46(3), 564570.

Solomon, M. R. (1983). The role of products as social stimuli: A symbolic interactionism perspective. Journal of consumer research, 10(3), 319-329.

Solomon, M. R. (1988). Mapping product constellations: A social categorization approach to consumption symbolism. Psychology and Marketing, 5(3), 233-258. 
Surrey, J. L. (1991). The self-in-relation: A theory of women's development. In J. V. Jordan, A. G. Kaplan, J. B. Miller, I. P. Stiver, \& J. L. Surrey (Eds.), Women's growth in connection: Writings from the stone center. New York: Guilford press.

Thompson, C. J. (1996). Caring consumers: gendered consumption meanings and the juggling lifestyle. Journal of consumer research, 22(4), 388-407.

Thompson, C. J., \& Haytko, D. L. (1997). Speaking of fashion: consumers' uses of fashion discourses and the appropriation of countervailing cultural meanings. Journal of consumer research, 24(1), 15-42.

Thompson, C. J., \& Hirschman, E. C. (1995). Understanding the socialized body: A poststructuralist analysis of consumers' self-conceptions, body images, and self-care practices. Journal of consumer research, 22(2), 139-153.

Thompson, S. K. (1975). Gender labels and early sex role development. Child Development, 46(2), 339-347.

Tian, K., \& Belk, R. W. (2005). Extended self and possessions in the workplace. Journal of consumer research, 32(2), 297-310.

Turner, J. C. (1985). Social categorization and the self-concept: A social cognitive theory of group behavior. Advances in group processes: Theory and research, 2, 77-122.

Üstüner, T., \& Holt, D. B. (2007). Dominated consumer acculturation: The social construction of poor migrant women's consumer identity projects in a Turkish squatter. Journal of consumer research, 34(1), 41-56.

vanDellen, M., R. , \& Hoyle, R. H. (2008). Possible selves as behavioral standards in selfregulation. Self and Identity, 7(3), 295-304.

Wakefield, K. L., \& Inman, J. J. (2003). Situational price sensitivity: the role of consumption occasion, social context and income. Journal of Retailing, 79(4), 199-212. 
Wan, E. W., Xu, J., \& Ding, Y. (2014). To be or not to be unique? The effect of social exclusion on consumer choice. Journal of consumer research, 40(6), 1109-1122.

Ward, S. (1974). Consumer socialization. Journal of consumer research, 1(2), 1-14.

Wattanasuwan, K. (2005). The self and symbolic consumption. Journal of American Academy of Business, 6(1), 179-184.

West, C., \& Zimmerman, D. H. (1987). Doing gender. Gender \& Society, 1(2), 125-151.

White, K., \& Dahl, D. W. (2006). To be or not be? The influence of dissociative reference groups on consumer preferences. Journal of Consumer Psychology, 16(4), 404-414.

White, K., \& Dahl, D. W. (2007). Are All Out-Groups Created Equal? Consumer Identity and Dissociative Influence. Journal of consumer research, 34(4), 525-536.

Wicklund, R. A., \& Gollwitzer, P. M. (1981). Symbolic self-completion, attempted influence, and self-deprecation. Basic and Applied Social Psychology, 2(2), 89-114.

Wicklund, R. A., \& Gollwitzer, P. M. (1982). Symbolic self completion. Hillsdale, NJ: Lawrence Erlbaum.

Wright, N. D., Claiborne, C. B., \& Sirgy, M. J. (1992). The effects of product symbolism on consumer self-concept. Advances in consumer research, 19(3), 11-13. 